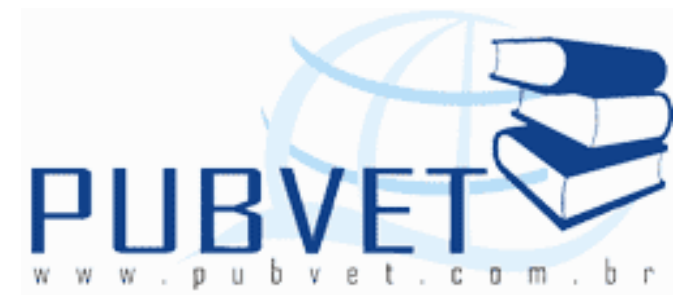

PUBVET, Publicações em Medicina Veterinária e Zootecnia.

\title{
Caracterização das propriedades agropecuárias no Municipio de Parnarama-MA
}
Wemmerson Luz da $\operatorname{Costa}^{1}$; Nilton Andrade Magalhães ${ }^{2}$; Gioto Ghiarone Terto e Sousa ${ }^{3}$

${ }^{1}$ Bacharel em Zootecnia, Instituto de Ensino Superior Multiplo, IESM, Timon, Maranhão.

${ }^{2}$ Docente, Instituto de Ensino Superior Multiplo, IESM, Timon, Maranhão.

${ }^{3}$ Mestrando, Programa de Pós-Graduação em Ciência Animal, Universidade Federal do Piauí, UFPI, Teresina, Piauí.

\section{Resumo}

A produção animal no Nordeste é fonte de alimentação e renda para a população, mas o manejo inadequado e fatores culturais ineficientes contribuem para que a pecuária tenha baixos índices zootécnicos. Foram entrevistados 21 pecuaristas. Parnarama está localizado na meso região Leste Maranhense, é essencialmente agropecuária, destacando-se a bovinocultura. $\mathrm{O}$ objetivo do trabalho foi caracterizar qualitativamente o nível de conhecimento técnico e traçar o perfil dos criadores. A pesquisa foi realizada no período de julho a agosto de 2010. Os resultados foram tabulados e feito média, percentagem e desvio padrão. De acordo com dados pesquisados no município há um predomínio de propriedades com menos de 100 ha. $76 \%$ das terras estão sob a mesma posse há mais de 20 anos. Ao avaliar as instalações e seus 
COSTA, W.L., MAGALHÃES, N.A. e SOUSA, G.G.T. Caracterização das propriedades agropecuárias no Municipio de Parnarama-MA. PUBVET, Londrina, V. 6, N. 31, Ed. 218, Art. 1454, 2012.

níveis de conservação, contatou-se que a maioria das propriedades apresenta estado de conservação regular apesar de terem sido construídos a mais de 10 anos. $66 \%$ dos produtores possui apenas o ensino fundamental incompleto. 0 controle zootécnico é feito em $28 \%$ das propriedades e $72 \%$ não realizam. 0 pagamento da mão de obra envolvida é feito através de partilha e salário em espécie com carteira assinada. Na utilização de maquinários $66 \%$ não as possuem. Na área de reprodução animal apenas 14,28\% das propriedades usam inseminação artificial. A vacinação do rebanho é feita contra tuberculose e brucelose em apenas $28,57 \%$. A vermifugação é feita de forma errada por $80,96 \%$. Conclui-se que a pecuária é predominantemente de corte, sem informação e sem infraestrutura adequadas e sem nenhum conhecimento sobre manejo.

Palavras-chave: bovinocultura, caracterização do rebanho, índices zootécnicos, manejo, pecuária.

\title{
Characterization of agricultural properties in the municipio of Parnarama-MA
}

\begin{abstract}
Livestock production in the Northeast is a source of food and income for the population, but the inadequate management and cultural factors that contribute to inefficient farming has low zootechnic rates. 21 ranchers were interviewed. Santa Barbara is located in the Eastern region of Maranhão is meso mainly agriculture, cattle. The objective of this work was to characterize the quality of the level of technical knowledge and profile of the creators. The survey was conducted in the period from July to August 2010. The results were tabulated and done average, percentage, and standard deviation. According to respondents in the municipality there is a predominance of properties with less than 100 ha. $76 \%$ of lands are under the same ownership for over 20 years. To assess the facilities and their levels of conservation, contacted that most
\end{abstract}


COSTA, W.L., MAGALHÃES, N.A. e SOUSA, G.G.T. Caracterização das propriedades agropecuárias no Municipio de Parnarama-MA. PUBVET, Londrina, V. 6, N. 31, Ed. 218, Art. $1454,2012$.

properties presents regular conservation status despite having been built over 10 years. $66 \%$ of producers have only incomplete elementary school. Breeding is done in control $28 \%$ of properties and $72 \%$ don't realize. The payment of labor involved is done through sharing and wages in kind with signed portfolio. $66 \%$ utilization of machinery has not. In the area of animal breeding only $14.28 \%$ of properties using artificial insemination. Herd vaccination against tuberculosis and brucellosis is made in only $28.57 \%$. The worming is done the wrong way by $80.96 \%$. It is concluded that the livestock is predominantly cut, no information and no appropriate infrastructure and without any knowledge about management.

Keywords: cattle, characterization of the herd, livestock, management, zootechnic rates.

\section{Introdução}

A produção animal na região Nordeste desempenha papel primordial no suprimento alimentar e geração de renda da população, no entanto, na maioria dos casos, é desenvolvida de forma empírica e extensiva, com baixos níveis tecnológicos. Esta criação é feita com pastagem nativa associada à forragem produzida dessa mesma vegetação, que apresenta baixa capacidade de suporte.

Um manejo nutricional inadequado e deficiente associados às práticas inadequadas de criação colabora para que os rebanhos sejam fortemente afetados e concorrem para os baixos índices zootécnicos, tais como baixa taxa de natalidade/ano agregada a elevada taxa de mortalidade desde o nascimento ao desmame, além de idade do primeiro parto e abate dos animais tardios.

Outro fator marcante na agropecuária da região é a necessidade do produtor de assegurar seu próprio sustento levando-os a adotarem sistemas de produção que pressionam os recursos renováveis além de sua intolerância ecológica com práticas predatórias. Assim, o extrativismo da cobertura vegetal, o super pastejo de áreas nativas e a exploração agrícola sem qualquer 
COSTA, W.L., MAGALHÃES, N.A. e SOUSA, G.G.T. Caracterização das propriedades agropecuárias no Municipio de Parnarama-MA. PUBVET, Londrina, V. 6, N. 31, Ed. 218, Art. 1454, 2012.

tipo de preocupação conservacionista concorrem também para os baixos índices sócios econômicos da região, refletindo em grandes transtornos ecológicos e exaustão da terra tornando-a, muitas vezes, improdutiva.

O município de Parnarama está localizado no Estado do Maranhão, a 375 km da capital São Luiz, e 75 km de Teresina, capital do Piauí; é essencialmente agropecuário produzindo, principalmente, madeira, arroz, farinha de mandioca, feijão, milho e manga. Na pecuária destaca-se a criação bovina que, há 72.021 cabeças. Portanto, a pecuária bovina ocupa uma posição de grande importância econômica uma vez que abastece todo o município e regiões circunvizinhas, inclusive fornecendo carne para o vizinho Estado do Piauí.

O objetivo do trabalho foi avaliar e caracterizar qualitativamente o nível de conhecimento técnico sobre a criação bovina no município de Parnarama MA e traçar o perfil dos produtores.

\section{Material e métodos}

O trabalho foi uma pesquisa de campo, realizada no período de julho a agosto de 2010, em Parnarama - MA. Para o seu desenvolvimento foram aplicados 21 questionários junto aos produtores, contendo questões subjetiva e objetiva, em fazendas localizadas no referido município.

Para realização da pesquisa, inicialmente, as fazendas foram divididas em três grupos: pequena, média e grande. Sendo consideradas pequenas as que apresentam até 100 ha, médias até 300 ha e acima desse valor considerada grande. As médias propriedades foram subdivididas em dois subgrupos as de 101 a 200 ha e de 201 a 300 ha, em função do grande número de propriedades nesse grupo. Foram selecionadas fazendas, de três a sete, em cada grupo de forma aleatória através de sorteio. 
COSTA, W.L., MAGALHÃES, N.A. e SOUSA, G.G.T. Caracterização das propriedades agropecuárias no Municipio de Parnarama-MA. PUBVET, Londrina, V. 6, N. 31, Ed. 218, Art. 1454, 2012.

Os resultados obtidos foram analisados, interpretados e tabulados em função das questões abordadas. Na análise estatística foram feitas as médias, porcentagens e desvio padrão dos dados.

\section{Resultados e discussão}

As propriedades rurais no Brasil apresentam-se distribuídas desuniformes mente, havendo predomínio de propriedades com 1000 ha ou mais. A situação do Estado do Maranhão não é diferente do quadro nacional, entretanto, podem-se verificar características diferenciadas nas diversas microrregiões que formam o Estado. Essas diferenças estão diretamente relacionadas a fatores econômicos, sociais e culturais.

De acordo com dados pesquisados em Parnarama - Ma, microrregião do Leste Maranhense, há predomínio de propriedades com menos de 100 ha, seguida das grandes propriedades, que são as que possuem mais de 300 ha (Tabela 1). A situação fundiária do município. Para o país que aponta as pequenas propriedades (com menos de $10 \mathrm{ha}$ ) ocupando apenas 2,7\% da área dos estabelecimentos rurais do país, enquanto que as grandes propriedades representam 43\%. Esta diferença está relacionada, principalmente, a heranças de terras que ficam concentradas nas mãos de poucos herdeiros em função de fatores socioculturais e ou econômicos.

Tabela 1. Área, em hectares, dos estabelecimentos rurais do município de Parnarama - MA.

\begin{tabular}{lcc}
\hline Tamanho (hectares) & Número de Propriedades & $\%$ \\
\hline De 01 a 100 & 7 & 33,3 \\
De101 a 200 & 5 & 24 \\
De 201 a 300 & 3 & 14,2 \\
Acima de 300 & 6 & 28,5 \\
\hline Total & 21 & 100 \\
\hline
\end{tabular}

Para quantificar o tamanho dos rebanhos foram distribuídos em três categorias: pequeno, médio e grandes pecuaristas. Os pequenos possuíam até 100 cabeças de gado bovino, representando mais da metade dos criadores 
COSTA, W.L., MAGALHÃES, N.A. e SOUSA, G.G.T. Caracterização das propriedades agropecuárias no Municipio de Parnarama-MA. PUBVET, Londrina, V. 6, N. 31, Ed. 218, Art. $1454,2012$.

(57\%) e os com mais de 200 cabeças representando apenas $19 \%$, a menor parcela de pecuaristas (Tabela 2). Verifica-se um antagonismo entre tamanho das propriedades $X$ rebanho, pois predominam as grandes propriedades e 0 maior número de criadores está nas pequenas propriedades o que demonstra uma subutilização das terras. Essa dissiparidade está relacionada há uma questão cultural de que a terra é sinônimo de poder e riqueza.

Dos pecuaristas pesquisados, cerca de $66,8 \%$ criam apenas bovinos (tabela 2). Os demais criam também caprinos $(9,5 \%)$, ovinos $(4,7 \%)$ e suínos $(19,0 \%)$.

Tabela 2. Tamanho do rebanho bovino distribuídos por grupo e número de proprietários (absoluto e percentual), de Parnarama - MA.

\begin{tabular}{lcc}
\hline $\begin{array}{l}\text { Tamanho do rebanho / } \\
\text { cabeça }\end{array}$ & Número de proprietários & $\begin{array}{c}\text { Número de proprietários } \\
\text { em \% }\end{array}$ \\
\hline De 01 a 100 & 12 & $57 \%$ \\
De 101 a 200 & 05 & $24 \%$ \\
Acima de 201 & 04 & $19 \%$ \\
\hline Total & 21 & $100 \%$ \\
\hline
\end{tabular}

O tempo de posse de uma terra está relacionado com a cultura de mantê-la em uma mesma família sendo passada de geração a geração. Em Parnarama esse tipo de cultura perpetua, permanecendo a posse da terra por longo período de tempo na mão de um mesmo proprietário, fato que atualmente está mudando em decorrência da chegada de indústria que está comprando as terras por preço relativamente baixo, mas que está sendo, no momento, um atrativo para os proprietários que a subutilizam. De acordo com a pesquisa, foi constatado que $76 \%$ delas estão sob a mesma posse há mais de 20 anos demonstrando uma estabilidade na sua posse (figura 1). 
COSTA, W.L., MAGALHÃES, N.A. e SOUSA, G.G.T. Caracterização das propriedades agropecuárias no Municipio de Parnarama-MA. PUBVET, Londrina, V. 6, N. 31, Ed. 218, Art. 1454, 2012.

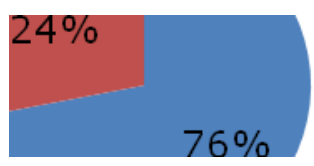

mais de 15 anos

mentre 5 e 15 anos

Figura 1: Tempo de posse das propriedades no município de Parnamara - MA.

As instalações de uma propriedade refletem diretamente o seu grau de organização e de tecnificação. As propriedades pesquisadas apresentam instalações em estado de conservação variando de regular a bom apesar de todas terem mais de dez anos de construção 52,39\% das propriedades apresentam estado regular de conservação, sendo assim classificadas como funcionais, mas com pouca estrutura adequada tornando-as fragilizadas; $47,61 \%$ apresentam instalações bem conservadas com aspecto íntegro em toda a estrutura observada.

Quanto ao nível de escolaridade dos proprietários $10 \%$ possuíam nível superior, $14 \%$ haviam cursado o ensino médio, $66 \%$ o ensino fundamental incompleto, e $10 \%$ não possuem escolaridade (figura 2). Esse baixo índice intelectual reflete diretamente no grau de tecnificação da fazenda, como afirma Grossi (1978) que o grau de instrução tem um efeito direto para a introdução de fatores modernos na produtividade rural.

Para Astudillo (1984), a tecnificação refere-se à utilização ou introdução de melhorias nos procedimentos, processos ou insumos destinados a incrementar a produtividade pecuária, sendo que o nível de tecnificação reflete as inversões feitas nos estabelecimento sem termos de recursos de capital. Os índices de tecnificação abordadas nas entrevistas foram: controle zootécnico, técnicas de reprodução, mecanização e Mão de obra. 
COSTA, W.L., MAGALHÃES, N.A. e SOUSA, G.G.T. Caracterização das propriedades agropecuárias no Municipio de Parnarama-MA. PUBVET, Londrina, V. 6, N. 31, Ed. 218, Art. 1454, 2012.

Analisando as informações obtidas, constatou-se que uma menor parte dos proprietários entrevistados recebia algum tipo de assistência técnica $(15 \%)$, realizada por técnico agrícola, zootecnista, agrônomo ou veterinário.

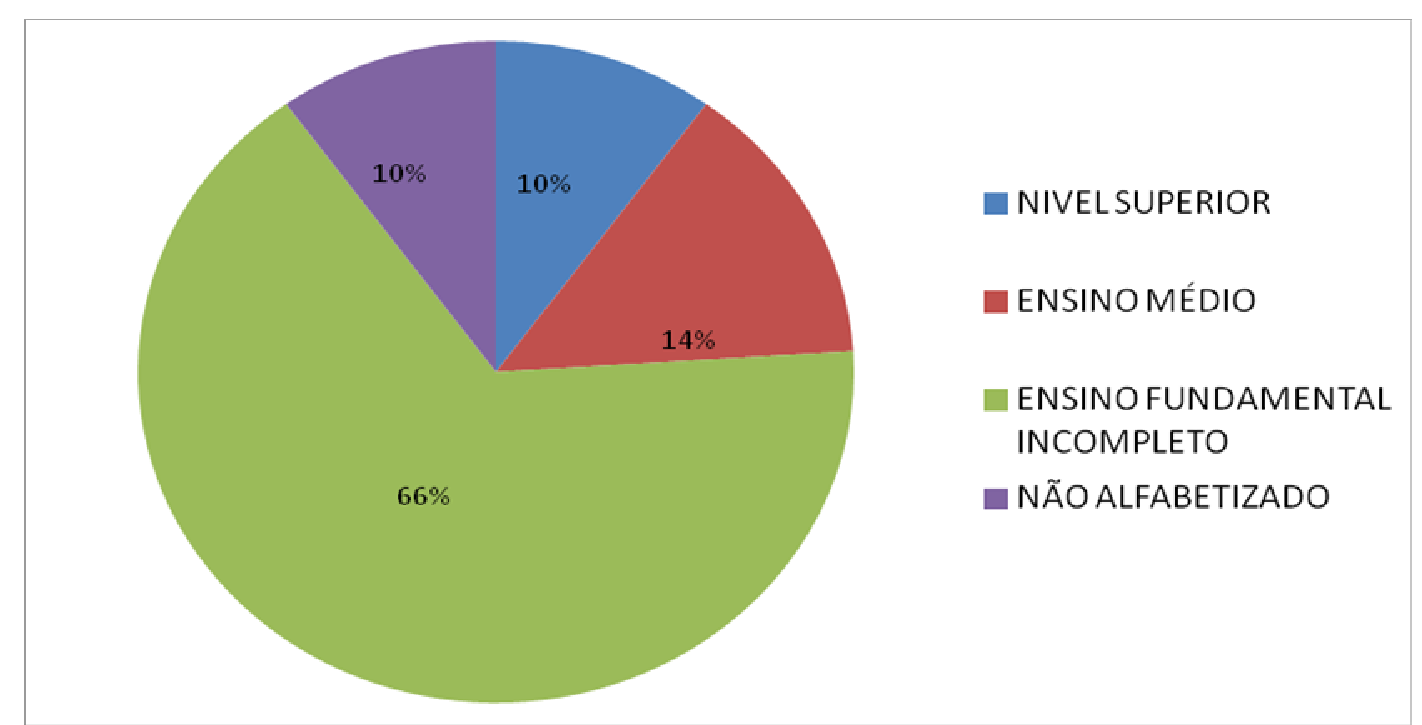

Figura 2. Níveis de escolaridade dos pecuaristas das fazendas pesquisadas em Parnarama - MA.

O controle zootécnico é uma forma de conhecer e avaliar produção e produtividade de um rebanho. Esse controle é feito em $28 \%$ das propriedades do município, sendo que $14 \%$ são realizados por programas softwares e os outros 14\% utilizam cadernos de arame para as anotações (figura 3). Considerando o tempo de uso do registro zootécnico observou-se que $50 \%$ realizam a menos de cinco anos e os outros a mais de 11 anos. Leite et al. (2000) em trabalho realizado no estado da Paraíba encontrou utilização de controle zootécnico nas propriedades estudadas bem superiores ao do município de Parnarama que foi de 55,07\% distribuídos em registros de fichas livros e computadores.

$72 \%$ das propriedades não utilizam nenhuma forma técnica de registro para controle. Segundo os pesquisados como conhecem todo o rebanho não se faz necessário nenhum tipo de controle: "as informações sobre o rebanho estão gravadas na cabeça". Alguns fazem anotações nas paredes, tábuas e pé direito dos currais. 
COSTA, W.L., MAGALHÃES, N.A. e SOUSA, G.G.T. Caracterização das propriedades agropecuárias no Municipio de Parnarama-MA. PUBVET, Londrina, V. 6, N. 31, Ed. 218, Art. 1454, 2012.

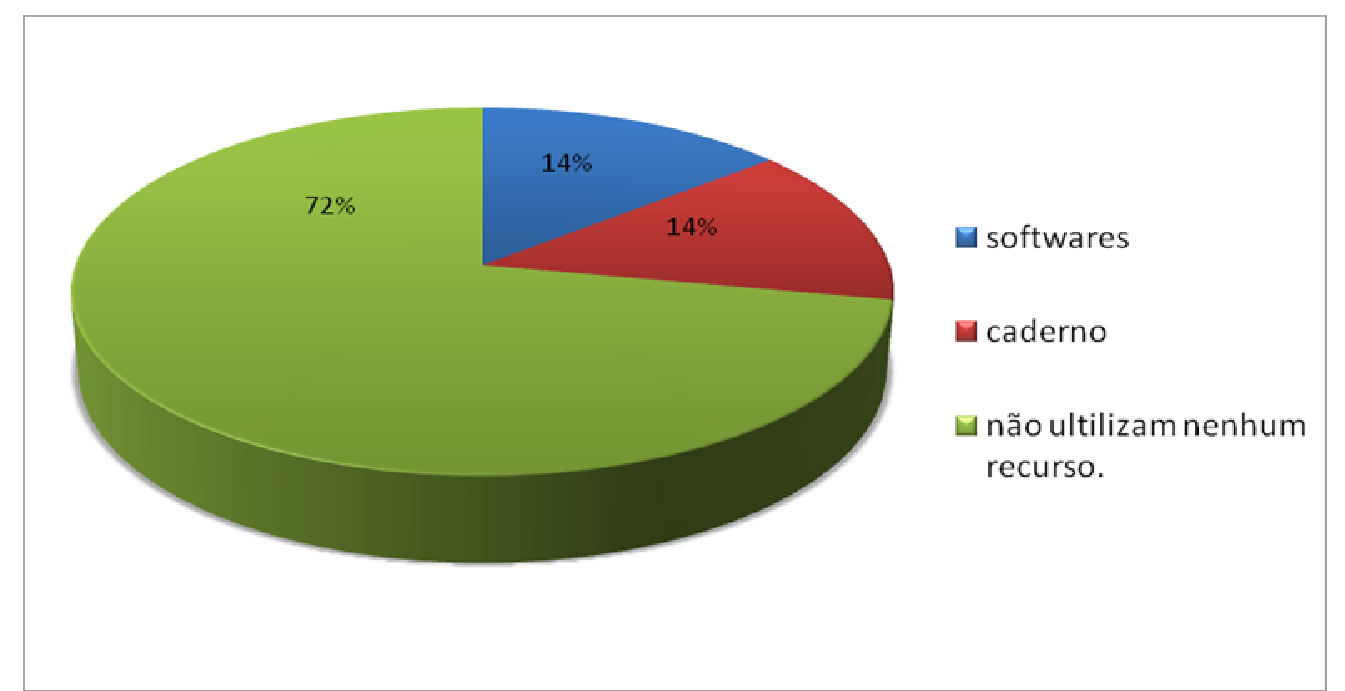

Figura 3. Controle zootécnico das fazendas pesquisadas do município de Parnarama - MA.

A análise da mão de obra envolvida no processo produtivo permite uma visão das relações de trabalho que dão suporte à caracterização do nível de inversão tecnológica da produção. O pagamento dos vaqueiros e tratadores é feito rotineiramente de duas formas: salário em espécie com carteira assinada e através de partilha das crias. Os que recebem salário em espécie representam $9,52 \%$ e os que recebem através de partilha são $76,2 \%$ (figura 4). A relação da partilha é de $3: 1$, o proprietário fica com três crias e o vaqueiro e ou tratador com uma. A partilha é de forma aleatória, permitindo que não haja prejuízo para nenhum dos envolvidos na relação. A partilha é histórica no Brasil, tendo registros desde o período colonial. Relatam que a partilha ou sorte era feita de cada quatro crias nascidas durante o percurso, sendo uma do vaqueiro, como forma de incentivá-lo a cuidar melhor e preservar o rebanho, pois assim, poderia montar seu próprio rebanho ou, ainda, arrendar terras para o cultivo. $14,28 \%$ são vaqueiros ou tratadores proprietários recebendo como pagamento toda sua produção de crias. 
COSTA, W.L., MAGALHÃES, N.A. e SOUSA, G.G.T. Caracterização das propriedades agropecuárias no Municipio de Parnarama-MA. PUBVET, Londrina, V. 6, N. 31, Ed. 218, Art. 1454, 2012.

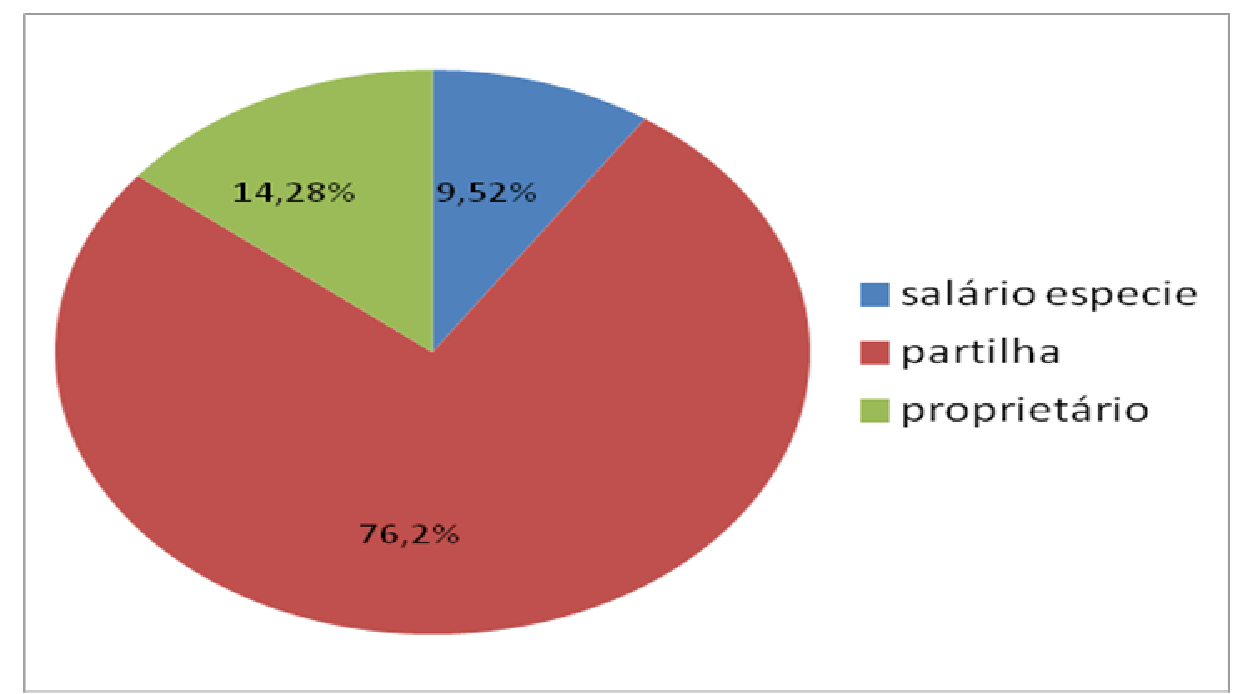

Figura 4. Remuneração de tratadores e vaqueiros das fazendas pesquisadas no município de Parnarama - MA.

A utilização de máquinas na execução das mais diversas operações, dentro de uma propriedade rural visa, principalmente, a realização de tarefas de uma forma mais rápida, eficiente e com maior conforto ao operador, permitindo aumento da capacidade individual de trabalho e produtividade (INTERURAL, 2010). Nas propriedades pesquisadas as maquinas encontradas foram: forrageira, motor gerador de energia, tratores, trator de esteira, roçadeira, plantadeira, arado, e bomba d'água.

Em 9,52\% das propriedades pesquisadas estão presentes todos os maquinários citados anteriormente; $23,8 \%$ possuem forrageira, motor, gerador e bomba d'água. Em $66,7 \%$ das propriedades não há nenhuma maquina o que demonstra $o$ baixo nível de tecnificação e a falta de investimento para melhoria da produção e produtividade. Leite et al. (2000), em estudo realizado no Estado da Paraíba encontrou um nível de tecnificação bem superior ao verificado em Parnarama, havendo a presença de tratores em $43,47 \%$, forrageira $97,1 \%$ e irrigação $49,27 \%$ (figura 5 ). As propriedades do município não utiliza sistema de irrigação. 
COSTA, W.L., MAGALHÃES, N.A. e SOUSA, G.G.T. Caracterização das propriedades agropecuárias no Municipio de Parnarama-MA. PUBVET, Londrina, V. 6, N. 31, Ed. 218, Art. 1454, 2012.

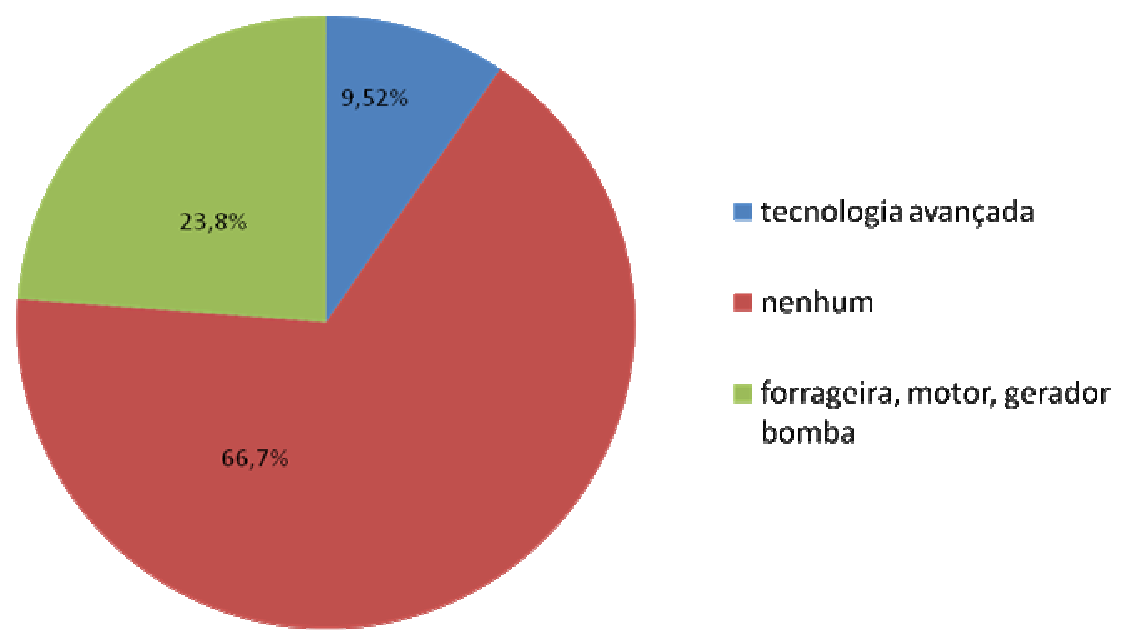

Figura 5. Utilização de maquinas agricolas nas fazendas pesquisadas em Parnarama - Ma.

As propriedades que não dispõem de maquinas suprem suas necessidades por meio de aluguel de tratores. Os demais maquinários inexistentes são substituídos por aparelhos rudimentares e manuais, assim sendo, também realizado por proprietários que não tem condições financeiras para alugar trator. Alguns, por questões culturais, realizam os trabalhos de forma bem rudimentar.

A utilização das queimadas é feita na grande maioria das propriedades o que reforça ainda mais a baixa tecnificação das mesmas contribuindo para manutenção de práticas culturais obsoletas de forma efetiva para uma menor produtividade nas propriedades do município em decorrência do baixo nível intelectual dos proprietários.

Em 14,28\% das propriedades pesquisadas faz-se o uso da inseminação artificial (IA); $28,58 \%$ dos proprietários não conhecem a técnica e 57,14\% faz uso de monta natural (MN) (figura 6). Nas propriedades que usam MN a relação touro/vaca é de 1:30, valor superior citado na literatura. De acordo com Fonseca (2000) a proporção touro vaca na pecuária é muito baixa, situando-se em torno de um touro para 20, no máximo, 25 vacas. 
COSTA, W.L., MAGALHÃES, N.A. e SOUSA, G.G.T. Caracterização das propriedades agropecuárias no Municipio de Parnarama-MA. PUBVET, Londrina, V. 6, N. 31, Ed. 218, Art. 1454, 2012.

Há uma relação direta entre tamanho da propriedade e uso da biotécnica IA, estando presente somente nas grandes propriedades, entretanto nem toda grande propriedade faz uso dessa técnica por falta de informação e fator cultural.

Ao contrário do município de Parnarama a IA tem uma boa aceitação no país principalmente na pecuária de corte. Há uma estimativa que no ano de 2006 foram inseminadas mais de um milhão de vacas em tempo fixo. Esses dados são estimados em função da falta de divulgação do uso da inseminação no país (ANUALPEC, 2008).

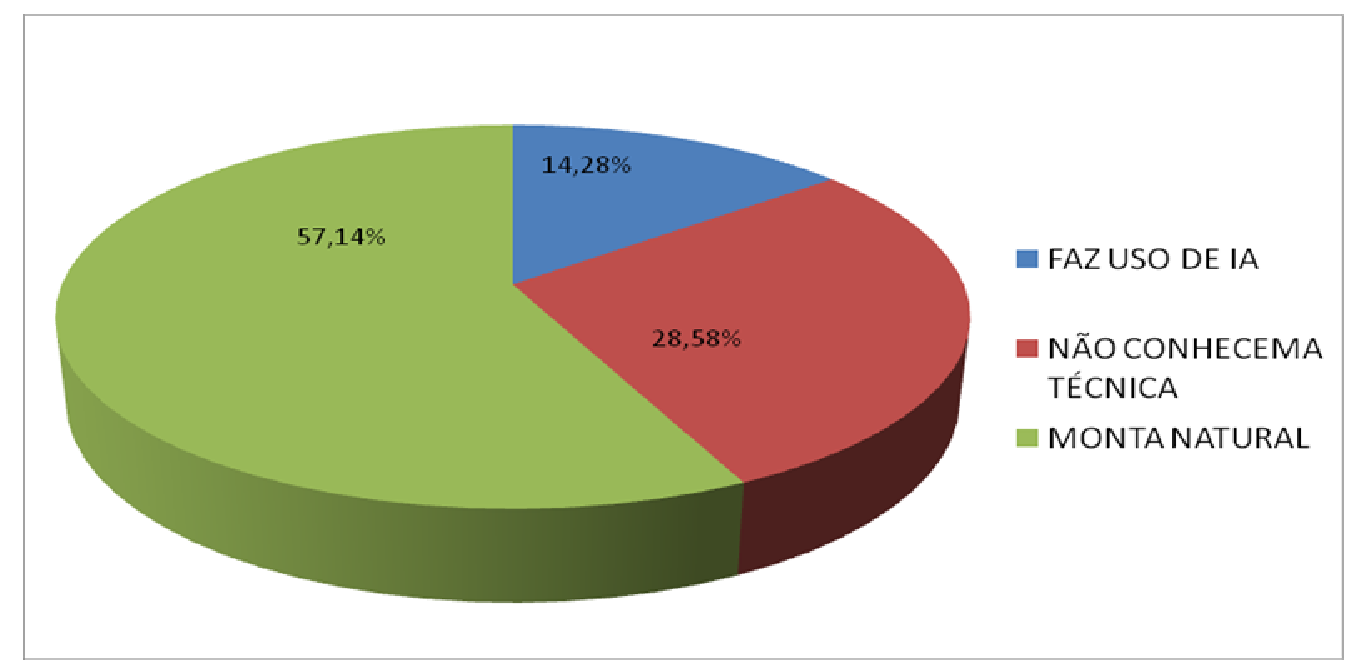

Figura 6. Utilização de inseminação artificial nas fazendas pesquisadas em Parnarama-MA.

Os bovinos podem ser afetados por várias doenças que causam grandes prejuízos aos criadores e a economia dos seus países de origem, devido à queda da produção e pela morte dos animais que as contraíram. Além disso, muitas dessas doenças podem ser transmitidas ao homem. Por esse motivo, elas devem ser combatidas e prevenidas, principalmente com o uso de vacinas especificas. Uma doença muito grave para os bovinos e que pode também ser transmitida ao homem é a brucelose, que é causada por uma bactéria ocasionando grandes perdas econômicas no rebanho. Sua incidência também pode ser controlada pelo uso de vacinas. O principal 
COSTA, W.L., MAGALHÃES, N.A. e SOUSA, G.G.T. Caracterização das propriedades agropecuárias no Municipio de Parnarama-MA. PUBVET, Londrina, V. 6, N. 31, Ed. 218, Art. 1454, 2012.

sintoma dessa doença é a ocorrência de abortos. Por este motivo é uma doença que pode causar grandes prejuízos, pois prejudica muito a produção do rebanho (INDEA-MT, 2005).

As vacinas contra a brucelose e a febre aftosa são consideradas obrigatórias, enquanto outras doenças que também podem ser controladas com o uso de vacinas não são, necessariamente, alvo de vacinações sistemáticas. Entre essas doenças pode-se citar o carbúnculo hemático, o carbúnculo sintomático (INDEA-MT, 2005). No município somente é realizado controle da vacina contra a febre aftosa (figura 7) embora haja ocorrência suspeita de raiva e brucelose.

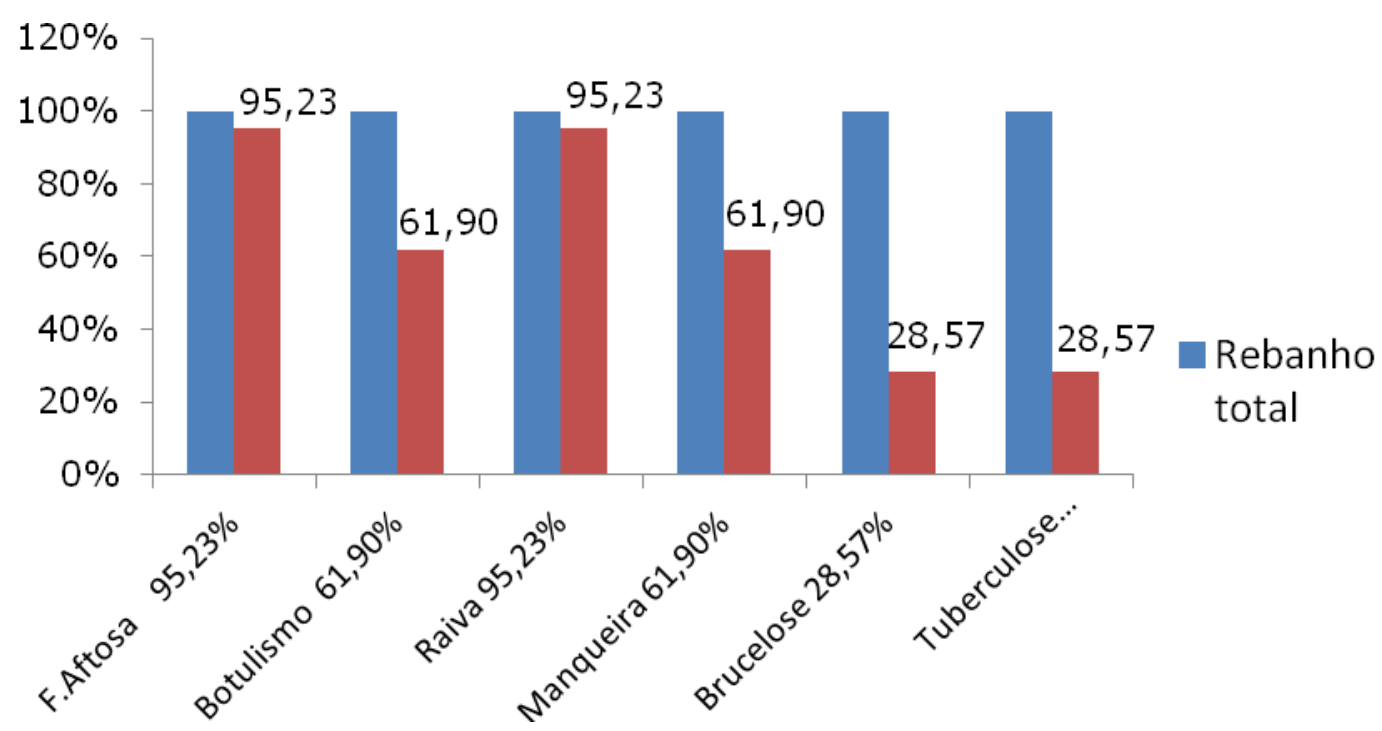

Figura 7. Vacinação do rebanho bovino nas fazendas pesquisadas em Parnarama-MA.

De acordo com os dados, $8,19 \%$ do rebanho bovino são imunizados contra febre aftosa, valor superior ao encontrado nessa pesquisa. Não há dados oficiais sobre o grau de imunização das demais patologias no município, mas o que se pode verificar é que apesar de não existir um programa oficial de vacinação, exceto da febre aftosa, há uma percentagem marcante de vacinação contra raiva, carbúnculo sintomático e botulismo. Mas a vacinação contra brucelose deve ser incrementada, pois é comum na região relatos de 
COSTA, W.L., MAGALHÃES, N.A. e SOUSA, G.G.T. Caracterização das propriedades agropecuárias no Municipio de Parnarama-MA. PUBVET, Londrina, V. 6, N. 31, Ed. 218, Art. 1454, 2012.

casos de aborto sem explicação aparente, fato que sugere poder estar associado a ocorrência da brucelose.

Leite et al. (2000), em trabalho realizado na Paraíba encontrou valores inferiores aos verificados em Parnarama - MA o qual justifica ser pelo falta de um programa de vacinação obrigatório que também não há nesse município, entretanto há uma maior expressividade de vacinação.

Os efeitos dos helmintos sobre os bovinos dependem da espécie e do grau de infecção, o qual, por sua vez, depende de diversos fatores, tais como as condições climáticas, solo, vegetação, tipo de exploração, raça e idade do animal, e o tipo de pastagem. Quando maciças, as infecções podem causar a morte dos animais, como no Sul do país, aonde chega a atingir a taxa de 10\% (EMBRAPA GADO DE CORTE, 1995).

O controle estratégico da verminose bovina é, por definição, preventivo e seus efeitos são notados somente a médio e em longo prazo. Para se chegar a um controle eficiente e econômico é necessário estudar a epidemiologia dos helmintos nas diferentes regiões ecológicas e, desta forma, conhecer melhor a dinâmica dos helmintos no animal e na pastagem (EMBRAPA GADO DE CORTE, 1995).

Dos proprietários pesquisados 19,04\% faz vermifugação duas vezes ao ano; uma no início do período chuvoso e outra no final desse período. A outra parte dos produtores faz uso de vermífugo aleatoriamente à medida que nota que os animais estão pálidos ou estão muito magros (figura 8). Como essa vermifugação é feita sem nenhuma orientação técnica não se pode levar em consideração a possibilidade desse quadro clínico ser ocasionado por outra patologia. Verifica-se que, mesmo entre os proprietários que vermifugam seu rebanho sistematicamente, não é feita de forma adequada, pois são preconizados pelo menos três vermifugações/ano nos meses maio, julho e setembro. Isto proporcionaria uma redução de $2 \% \mathrm{em}$ mortalidade e um ganho médio de $41 \mathrm{~kg}$ de peso vivo por animal, no abate (EMBRAPA GADO DE CORTE, 1995). 
COSTA, W.L., MAGALHÃES, N.A. e SOUSA, G.G.T. Caracterização das propriedades agropecuárias no Municipio de Parnarama-MA. PUBVET, Londrina, V. 6, N. 31, Ed. 218, Art. 1454, 2012.

A ação das verminoses sobre os bovinos pode comprometer a produtividade dos rebanhos em diferentes graus e atingir perdas econômicas consideráveis já que induz o atraso do crescimento, diminuição do ganho ou perda de peso e a predisposição a outras doenças (PEREIRA et al., 2007). Os sinais observados pelos proprietários podem ser em decorrência de doenças secundárias às verminoses, doenças carênciais ou outras.

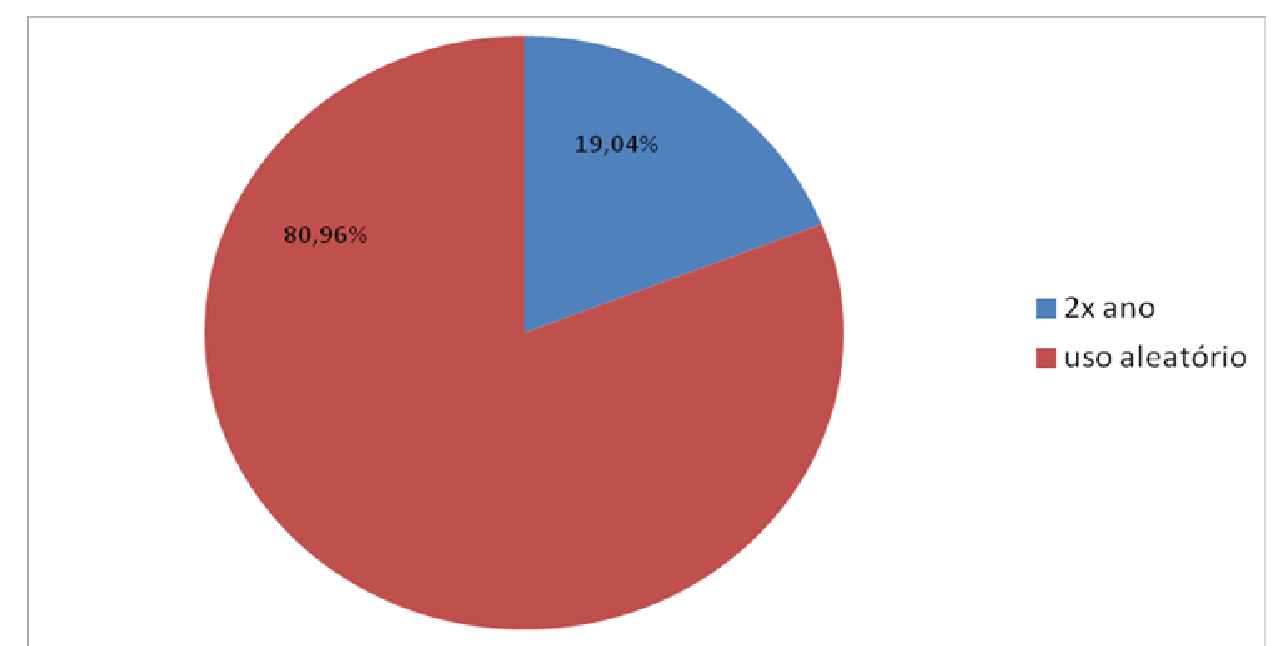

Figura 8. Vermifugação do rebanho bovino nas fazendas pesquisadas em Parnarama-MA.

Em relação ao tratamento de animais doente na propriedade apenas $7,5 \%$ chamam o médico veterinário do órgão responsável; outros $7,5 \%$ possuem veterinário disponível 24 horas. Cerca de 63\% dos proprietários entrevistados agem por conta própria, usam medicações caseiras (limão,aguardente, raízes de plantas nativas, "banhas de animais silvestres" ) e outros medicamentos de fabricação industrial, entre os mais citados na pesquisa estão o antitóxico e Stimovit (solução concentrada de vitaminas, minerais e glicose); Outros $22 \%$ dos entrevistados preferem pedir opinião ao vizinho "mais experiente" (figura 9).

A questão cultural é um fator preponderante e determinante na conduta frente a um animal doente. Observou-se que apenas uma pequena parcela dos criadores chama o médico veterinário quando há animais doentes, isso se deve, sobretudo à cultura de primeiro tomar suas medidas de tratamento de 
COSTA, W.L., MAGALHÃES, N.A. e SOUSA, G.G.T. Caracterização das propriedades agropecuárias no Municipio de Parnarama-MA. PUBVET, Londrina, V. 6, N. 31, Ed. 218, Art. 1454, 2012.

acordo com o seu conhecimento empírico passado de geração a geração e, somente, quando não resolve é que se busca ajuda médico veterinária, o que muitas vezes o problema já não é mais possível ser solucionado.

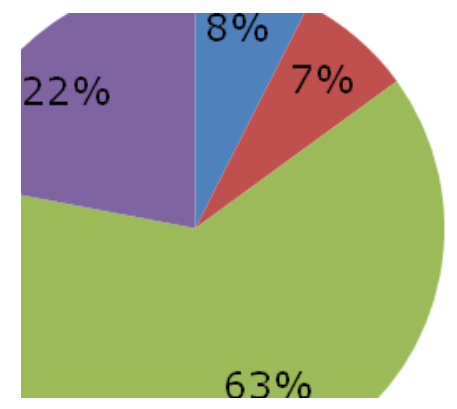

- Chama o vaterinario

- Chama o vaterinario (AGED)

agem por conta própria

Pede opinião ao vizinho

Figura 9. Conduta dos criadores pesquisados em Parnarama- MA com animais enfermos.

\section{Conclusão}

O município de Parnarama-MA apresenta uma pecuária predominantemente de corte. Há falta de conhecimento técnico e infraestrutura adequada para avaliar a produção e a produtividade.

Não possuem informações mínimas necessárias sobre o manejo alimentar, sanitário e reprodutivo do rebanho. O desconhecimento do produtor sobre o real potencial produtivo do rebanho e os fatores culturais dificulta a adoção de tecnologias mais avançadas e biotecnologias.

\section{Referências bibliográficas}

ABRAHÃO, J. J. S. et al. Características de carcaças e da carne de tourinhos submetidos a dietas com diferentes níveis de substituição do milho por resíduo úmido da extração da fécula de mandioca. Revista Brasileira de Zootecnia, v.34, n.5, p.1640-1650, 2005.

ANUALPEC 2009. Anuário Estatístico da Pecuária de Corte. FNP - Consultoria \& Comércio. São Paulo: FNP, 2009. 
ANUALPEC 2008. Anuário Estatístico da Pecuária de Corte. FNP - Consultoria \& Comércio. São Paulo: FNP, 2008.

ASTUDILLO, V. M. Formas de Organização como determinantes de risco de febre aftosa. A Hora Veterinária, v.3, p. 11-20,1984.

BRASIL. Ministério do Desenvolvimento, Indústria e Comércio. Secretaria do Desenvolvimento da Produção. Fórum da competitividade da cadeia produtiva de couros e calçados: diagnóstico. $2006 . \quad$ Disponível em: <http://www. desenvolvimento.gov.br/arquivo/sdp/proAcao/forCompetitividade/docInstalacoes /diagccouro.pdf>. Acesso em: 25 nov. 2010.

BEEFWORD. A carne bovina esta mais cara em São Luis. Disponível em:< http://beefworld.com.br/noticias/post/carne-bovina-esta-cara-e-em-falta-em-sao-luis-ma>. Acesso em 14/11/2010.

EMBRAPA GADO DE CORTE (Empresa Brasileira de Pesquisa Agropecuária). Verminose bovina: Ocorrência Controle $\quad$ Estratégico. 1995 Disponível em:<http://www.cnpgc.embrapa.br/publicacoes/divulga/GCD07.html $>$. acesso em $\underline{15 / 11 / 2010 .}$.

FERREIRA, M. B. D.; MOURÃO, G. B.; LOPES, B. C. Duração da gestação em zebuínos inseminados com touros da raça holandesa. In: XV ENCONTRO DE PESQUISA, Anais..., 1995. p.143.

FONSECA, V. O. O touro no contexto da eficiência reprodutiva do rebanho. Informe Agropecuário, v. 21, p. 48-63, 2000.

GROSSI, M. S. Fatores de educação e status ocupacional associados à renda do pequeno agricultor. Viçosa, MG, 1978. 83f. Tese (Magister Science) - Universidade Federal de Viçosa, MG, 1978.

IBGE. Instituto Brasileiro de Geografia e Estatística, 2007. Disponível em: $<$ http://www.ibge.gov.br/home/presidencia/noticias/noticia visualiza.php?id noticia $=1464$ \&id pagina=1>>. Acesso em: 02/11/2010.

INTERURAL, $2010 . \quad$ Disponível em: $<<$ http: www.interural.com/interna.php?referencia=revistas $>>$. Acesso em: 02/11/2010.

JARDIM, V. R. Curso de Bovinocultura. $4^{a}$ ed. Campinas: Instituto Campineiro de Ensino Agrícola, 2001.

JANK, S. M. Programa de estudo dos negócios do sistema agroindustrial: Competitividade do sistema agroindustrial do leite, São Paulo: USP, 1997. 28p.

LEITE, M. H. R. et al. Perfil Produtivo- Sanitário de Propriedades Produtoras de Bovinos no Estado da Paraíba, Brasil, 2000. Ciência Animal Brasileira, v.5, n. 4, p. 199-209, out/dez.2004.

LIMA, R. C. A. et al. Febre aftosa: impacto sobre as exportações brasileiras de carnes e o contexto mundial das barreiras sanitárias. São Paulo: ICONE, CPEA/ESALQ/USP, out. 2005. 
MIRANDA, S. H. G. Quantificação dos efeitos das barreiras não tarifárias sobre as exportações brasileiras de carne bovina. Piracicaba. 2001. Tese (Doutorado) - Escola Superior de Agricultura "Luiz de Queiroz", Universidade de São Paulo. 237 p.

OLIVEIRA, L. M.; SARANTÓPOUlOS, C. I. G. L.; CUNHA, D. G.; MOREIRA, C. Q.; LEMOS, A. B. Diagnostico da qualidade tecnológica de embalagens plásticas barreira a gases utilizadas para preservação de produtos cárneos. Campinas: CETEA - ITAL, p.31, 2003.

PEREIRA, M. J. S. $t$ al. Concepções do processo saúde/doença na produção familiar: uma abordagem epidemiológica qualitativa. Revista da Universidade Rural, v. 21, n. 1-2, p. 117-125, 2007. (Série Ciências da Vida).

INDEA-MT. Instituto de Defesa Agropecuária do Estado do Mato Grosso. Disponível em: < http:// www.indea.nmt.gov.br/html/noticia>. Acesso em 10 de novembro de 2010.

TORRES, A. de P. Melhoramento dos Rebanhos. 4a. ed. São Paulo: Nobel, 1986.

WILDER, J. S.; VAN VLECK, L. D. Relative economic values assigned to milk, fat test and type in pricing of bulls semen. Journal Dairy Sciense. n.71, p.492-497, 1988. 